\title{
MBE growth of HgCdTe on GaSb substrates for application in
}

\section{next generation infrared detectors}

R. Gu, J. Antoszewski, W. Lei, I. Madni, G. Umana-Membreno, L. Faraone

School of Electrical, Electronic and Computer Engineering, The University of Western Australia, Crawley, 6009, WA, Australia

Abstract

HgCdTe has dominated the high performance end of the IR detector market for decades. At present, the cost to fabricate $\mathrm{HgCdTe}$ based advanced infrared devices is relatively high. One approach to address this problem is to use cost effective alternative substrate, mainly Si and GaAs. Recently, GaSb has emerged as a new alternative with better lattice matching. In this paper, recent progress in molecular beam epitaxial (MBE) growth of $\mathrm{HgCdTe}$ infrared material at UWA is reported. HgCdTe has been grown on GaSb substrates by MBE, and has shown a lower Etch Pit Density (EPD) and higher minority carrier lifetime in comparison to other alternative substrates. This result makes GaSb an interesting and promising alternative substrate material for $\mathrm{HgCdTe}$ epitaxy. 
Key words: $\mathrm{A} 3 . \mathrm{MBE}, \mathrm{HgCdTe}$, alternative substrate, GaSb, EPD, lifetime

\section{Introduction}

Currently, $\mathrm{Cd}_{0.96} \mathrm{Zn}_{0.04} \mathrm{Te}(\mathrm{CZT})$ substrates are the preferred substrates for fabricating high performance $\mathrm{HgCdTe}$ infrared focal plane arrays (IRFPAs) due to their nearly zero lattice mismatch with $\mathrm{HgCdTe}$. However, they suffer some serious limitations such as small wafer size, high cost, relatively poor quality, low mechanical strength, and low thermal conductivity. Therefore, in recent years researchers have trialed alternative substrates in order to overcome the limitations suffered by CZT. Three main alternative substrates have been studied, e.g. Si [1-3], Ge [4-5] and GaAs [6-8], and mid-wave infrared HgCdTe detectors grown on these alternative substrates have demonstrated similar performance to those grown on CZT. However, lattice and thermal mismatch has become increasingly important due to the industry trend towards smaller pixel size and larger detector arrays. Stress due to lattice and thermal mismatch is an important issue in epitaxially-grown semiconductors. It leads to mismatch defects such as dislocations which are known to be the source of effective recombination and have impact 
on yield and electro-optical properties of the device [9-10]. Due to the large lattice mismatch between $\mathrm{HgCdTe}$ and the alternative substrates, a large dislocation density is observed, which reduces the performance of HgCdTe infrared detectors. Therefore, new alternative substrates are needed for growth of high quality HgCdTe materials. [11-12]

Figure 1 shows the lattice constant and coefficient of thermal expansion (CTE) of several potential alternative substrates. [13] The lattice constant mismatch between $\mathrm{GaSb}$ and $\mathrm{HgCdTe}$ is much smaller than that of $\mathrm{Si}, \mathrm{Ge}$ and GaAs. In addition, the CTE mismatch of $\mathrm{GaSb} / \mathrm{HgCdTe}$ is comparable to that of $\mathrm{Ge} / \mathrm{HgCdTe}$ and $\mathrm{GaAs} / \mathrm{HgCdTe}$ and much smaller than $\mathrm{Si} / \mathrm{HgCdTe}$. Therefore, in principle, $\mathrm{HgCdTe}$ grown on GaSb substrates should result in lower dislocation densities than if grown on other alternative substrates.

\section{Experimental Growth and Characterization}

To evaluate the feasibility of GaSb alternative substrates for growing high quality materials, $\mathrm{HgCdTe}$ has been grown using a Riber 32P MBE system. For comparison, $\mathrm{HgCdTe}$ materials have also been grown on GaAs and CdZnTe substrates (structures illustrated in Figure 2). In the case of GaAs substrates, due to higher lattice mismatch than GaSb, 
a low temperature ZnTe nucleation technique was introduced to prevent twin generation (Fig. 2c). An non-optimized $\mathrm{HgCdTe} / \mathrm{CdTe} / \mathrm{GaAs}$ structure was also grown for comparison (Fig. 2b).

Both GaAs and GaSb 211(B) substrates were epitaxy-ready from Wafer Technology Ltd. The CdZnTe substrates were etched in $0.5 \%$ Bromine-Methanol solution tobremove any oxidde layer on the sidrface, and then rinsed in methanol followed by deionized (DI) water. All substrates were pre-baked at a temperature of $150^{\circ} \mathrm{C}$ before thermal cleaning. After thermal cleaning, a reflection high-energy electron diffraction (RHEED) system was used to check the surface quality before sample growth. During growth, the Rheed system showed a clean and smooth growth front on GaSb, CZT and optimized GaAs substrates.

$\mathrm{HgCdTe}$ composition and thickness of each layer was extracted using the Fourier transform infrared spectroscopy (FTIR) technique. It showed that all four samples had comparable parameters (Tab.3). The FWHM of XRD rocking curve for $\mathrm{HgCdTe}$ on CdZnTe substrate is much narrower than that on GaSb and GaAs substrates, due to higher lattice mismatch for these two alternative substrate materials.

The EPD experiment was performed by wet etching using Chen's recipe $\left(\mathrm{H}_{2} \mathrm{O}: \mathrm{HCL}: \mathrm{HNO}_{3}: \mathrm{K}_{2} \mathrm{CR}_{2} \mathrm{O}_{7}=80 \mathrm{ml}: 10 \mathrm{ml}: 20 \mathrm{ml}: 8 \mathrm{~g}\right)$ for $3 \mathrm{mins}$ 
[14], followed by rinsing with DI water and drying with N2 before checking under a 1000x microscope. The EPD on $\mathrm{HgCdTe} / \mathrm{CdTe} / \mathrm{GaSb}$ was much lower than that on GaAs substrate (Figure 3). In spite of the fact that the epitaxy process on GaSb has not yet been optimized, the EPD showed that $\mathrm{HgCdTe}$ grown on GaSb substrates resulted in a considerable decrease of native dislocations in $\mathrm{HgCdTe}$.

In $\mathrm{HgCdTe}$ materials, the minority carrier lifetime is a function of material x-value, defect types and density, conductivity type, and carrier concentration. For a certain $\mathrm{x}$-value and carrier concentration, the lifetime will roughly reflect the defect density in the $\mathrm{HgCdTe}$ material. Minority carrier lifetimes were measured using the photoconductive decay technique. Note that no post-growth annealing or surface passivation layer was applied on any of the samples. To avoid sweep-out effects, the sample biasing was kept low (300 mV), and all photoconductive decay curves were fitted exponentially to obtain the minority carrier lifetimes.

Several different recombination mechanisms determine the photo-generated minority carrier lifetime in $\mathrm{HgCdTe}$, such as Auger, radiative, and Shockley-Read-Hall mechanisms, which have been discussed extensively in the literature [15-21]. The extracted lifetime 
values, from the temperature dependent photoconductive decay measurement results, are illustrated in Figure 4. $\mathrm{HgCdTe}$ grown on $\mathrm{GaSb}$ substrates has a lifetime of around $900 \mathrm{~ns}$ at $77 \mathrm{~K}$. The lifetime results showed a similar trend of that on EPD, that $\mathrm{HgCdTe}$ grown on GaSb has a higher quality than that on GaAs.

Figure 5 shows the experimental EPD and minority carrier lifetime in mid-wave infrared $\mathrm{HgCdTe}$ layers grown on different substrates vs lattice mismatch of $\mathrm{HgCdTe}$ and substrates. Note that the EPD of $\mathrm{HgCdTe}$ grown on different substrates is taken from the literature [22-27]. The curve plotted in Figure 6 is only for eye guidance and easy comparison, and does not have physical meaning.

It is observed that the EPD decreases and lifetime increases with reducing lattice mismatch between $\mathrm{HgCdTe}$ and the substrate. The EPD measured on $\mathrm{HgCdTe} / \mathrm{CdTe} / \mathrm{GaSb}$ samples was significantly lower in comparison to the values measured on un-optimized GaAs substrates, and being a factor of 3 lower than on the GaAs sample with an optimized low-temperature ZnTe nucleation layer. The results from lifetime measurement also consistent with these results. Considering that the HgCdTe epitaxial growth process on GaSb has yet to be optimized, the lower EPD and higher lifetime values for $\mathrm{HgCdTe}$ grown on $\mathrm{GaSb}$ 
substrates are likely to be directly linked to a considerable decrease in native dislocation density in the $\mathrm{HgCdTe}$ layer, suggesting that this approach has potential future application for producing high performance devices and high-yield IRFPAs.

\section{Conclusion}

In this work, GaSb has been investigated as a new alternative substrate for the epitaxial growth of $\mathrm{HgCdTe}$ infrared materials. Results obtained for GaSb demonstrate its potential as an alternative substrate for $\mathrm{HgCdTe} / \mathrm{CdTe}$ growth. MBE growth of $\mathrm{HgCdTe} / \mathrm{CdTe}$ on $\mathrm{GaSb}$ and GaAs has demonstrated that the $\mathrm{HgCdTe}$ material quality on $\mathrm{GaSb}$ is comparable to or slightly better than that on GaAs substrates, a growth technology that has been developed for decades. Further, XRD, EPD and lifetime characterization of the $\mathrm{HgCdTe}$ epitaxial layers indicate that fewer dislocations are generated at the $\mathrm{GaSb} / \mathrm{CdTe} / \mathrm{HgCdTe}$ interface in comparison to $\mathrm{GaAs} / \mathrm{CdTe} / \mathrm{HgCdTe}$. The experimental observations and simulation analysis clearly indicate that GaSb shows great promise for potential application in this area. In future work, the MBE growth parameters of $\mathrm{HgCdTe} / \mathrm{CdTe} / \mathrm{GaSb}$ structures will be optimized 
experimentally in an attempt to improve on the preliminary results presented in this paper.

\section{ACKNOWLEDGEMENTS}

This work was supported by the Australian Research Council

(FT130101708, DP150104839), and Universities Australia DADD German

Research Cooperation program (2014-2015), and UWA Research

Collaboration Awards (2016). Facilities used in this work are supported

by the WA node of Australian National Fabrication Facility (ANFF).

\section{REFERENCES}

[1] T. J. de Lyon, J. E. Jensen, M. D. Gorwitz, C. A. Cockrum, S. M. Johnson, G. M. Venzor, "MBE growth of HgCdTe on silicon substrates for large-area infrared focal plane arrays: A review of recent progress", J. Electronic Materials, 1999, 28(6): 705

[2] G. Brill, S. Velicu, P. Boieriu, Y. Chen, N. K. Dhar, T. S. Lee, Y. Selamet, S.

Sivananthan, "MBE growth and device processing of MWIR HgCdTe on large area Si substrates", J. Electronic Materials, 2001, 30(6): 717

[3] J. B. Varesi, R. E. Bornfreund, A. C. Childs, W. A. Radford, K. D. Maranowski, J. M. Peterson, S. M. Johnson, L. M. Giegerich, T. J. de Lyon, J. E. Jensen, "Fabrication of high-performance large-format MWIR focal plane arrays from MBE-grown $\mathrm{HgCdTe}$ on 4" silicon substrates” , J. Electronic Materials, 2001, 30(6): 566

[4] P. Ferret, J. P. Zanatta, R. Hamelin, S. Cremer, A. Million, M. Wolny, G. Destefanis, "Status of the MBE technology at leti LIR for the manufacturing of HgCdTe focal plane arrays", J. Electronic Materials, 2000, 29(6): 641

[5] J. P. Zanatta, G. Badano, P. Ballet, C. Largeron, J. Baylet, O. Gravrand, J. Rothman, P. Castelein, J. P. Chamonal, A. Million, G. Destefanis, S. Mibord, E. Brochier, P. Costa, "Molecular beam epitaxy growth of HgCdTe on Ge for thirdgeneration infrared detectors", J. Electronic Materials, 2006, 35(6): 1231 
[6] L. He, L. Chen, Y. Wu, X.L. Fu, Y.Z. Wang, J. Wu, M.F. Yu, J.R. Yang, R.J. Ding, X.N. Hu, Y.J. Li, Q.Y. Zhang, "MBE HgCdTe on Si and GaAs substrates", J. Crystal Growth, 2007, 301-302: 268-272

[7] R.N. Jacobs, C. Nozaki, L.A. Almeida, M. Jaime-Vasquez, C. Lennon, J.K. Markunas, D. Benson, P. Smith, W.F. Zhao, D.J. Smith, C. Billman, J. Arias, J. Pellegrino, "Development of MBE II-VI Epilayers on GaAs(211)B", J. Electronic Materials. 2012, 41(10): 2707

[8] J.D. Benson, L.O. Bubulac, P.J. Smith, R.N. Jacobs, J.K. Markunas, M. JaimeVasquez, L.A. Almeida, A. Stoltz, J.M. Arias, G. Brill, Y. Chen, P.S. Wijewarnasuriya, S. Farrell, U. Lee, "Growth and Analysis of HgCdTe on Alternate Substrates", J. Electronic Materials, 2012, 41(10): 2971.

[9] W. Lei, J. Antoszewski, and L. Faraone, Appl. Phys. Rev., 2, 041303 (2015).

[10] R. Gu, W. Lei, J. Antoszewski, I. Madni, G. Umana-Membreno, L. Faraone, "Recent progress in MBE grown HgCdTe materials and devices at UWA", Proc. SPIE 9819, 981912 (2016); doi:10.1117/12.2222997.

[11] W. Lei, R. J. Gu, J. Antoszewski, J. Dell, L. Faraone, “GaSb: A New Alternative Substrate for Epitaxial Growth of HgCdTe", J. Electronic Materials, 2014, 43(8): 27882794

[12] W. Lei, R.J. Gu, J. Antoszewski, J. Dell, G. Neusser, M. Sieger, B. Mizaikoff, and L. Faraone, "MBE Growth of Mid-wave Infrared HgCdTe Layers on GaSb Alternative Substrates", J Electron Mater., 44, 3180 (2015).

[13] R. Gu, W. Lei , J. Antoszewski, L. Faraone, "Investigation of Substrate Effects on Interface Strain and Defect Generation in MBE-Grown HgCdTe", J Electronic Materials, (2016), doi:10.1007/s11664-016-4558-6

[14] J.S. Chen, US patent, (No.4, 897, 1990), p152

[15] M. A. Kinch, M. J. Brau, and A. Simmons, "Recombination mechanisms in 814- $\mu \mathrm{m}$ HgCdTe," J. Appl. Phys. 72, 4261 (1992).

[16] J. S. Blakemore, Semiconductor Statistics (Pergaman, New York, 1962), p. 196.

[17] I. M. Baker, F. A. Capocci, D. E. Charlton, and J. T. M.

Wotherspoon, "Recombination in cadmium mercury telluride photodetectors," Solid-State Electron. 21, 1475 (1978).

[18] M. Y. Pines and O. M. Stafsudd, "Recombination process in intrinsic semiconductors using impact ionization capture cross sections in indium antimonide and mercury cadmium telluride," Infrared Phys. 20, 73 (1980).

[19] W. Shockley and W. T. Read, "Statistics of the recombinations of holes and electrons," Phys. Rev. 87, 835 (1952).

[20] C. T. Sah and W. Shockley, "Electron-hole recombination statistics in semiconductors through flaws with many charge conditions," Phys. Rev. 109, 1103 (1958)

[21] I. Madni, G. A. Umana-Membreno, W. Lei, R. Gu, J. Antoszewski, and L. Faraone, "Minority carrier lifetime in iodine-doped molecular beam epitaxy-grown HgCdTe", Applied Physics Letters 107, 182107 (2015); doi: 10.1063/1.4935154 [22] J.D. Benson, L.O. Bubulac, P.J. Smith, R.N. Jacobs, J.K. Markunas, M. JaimeVasquez, L.A. Almeida, A.J. Stoltz, P.S. Wijewarnasuriya, G. Brill, Y. Chen, U. Lee, M.F. Vilela, J. Peterson, S.M. Johnson, D.D. Lofgreen, D. Rhiger, E.A. Patten, and P.M. Goetz. "Characterization of Dislocations in (112) B HgCdTe/CdTe/Si ", J Electron Mater., 39(7): 1080-1086 (2010). 
[23] M. Carmody, A. Yulius, D. Edwall, D. Lee, E. Piquette, R. Jacobs, D. Benson, A. Stoltz, J. Markunas, A. Almeida, and J. Arias. "Recent progress in MBE growth of CdTe and HgCdTe on (211) B GaAs substrates", J Electron Mater., 41(10): 2719-2724 (2012).

[24] M. Carmody, J.G. Pasko, D. Edwall, R. Bailey, J. Arias, M. Groenert, L.A. Almeida, J.H. Dinan, Y. Chen, G. Brill, and N.K. Dhar. "LWIR HgCdTe on Si detector performance and analysis", J Electron Mater., 35(6): 1417-1422 (2006).

[25] D. Edwall, E. Piquette, J. Ellsworth, J. Arias, C.H. Swartz, L. Bai, R.P. Tompkins, N.C. Giles, T.H. Myers, and M. Berding. "Molecular beam epitaxy growth of highquality arsenic-doped HgCdTe", J Electron Mater., 33(6): 752-756 (2004).

[26] M. Carmody, J.G. Pasko, D. Edwall, R. Bailey, J. Arias, S. Cabelli, J. Bajaj, L.A. Almeida, J.H. Dinan, M. Groenert, A.J. Stoltz, Y. Chen, G. Brill, and N.K. Dhar. "Molecular beam epitaxy grown long wavelength infrared HgCdTe on Si detector performance", J Electron Mater., 34(6): 832-838 (2005).

[27] S.M. Johnson, A.A. Buell, M.F. Vilela, J.M. Peterson, J.B. Varesi, M.D. Newton, G.M. Venzor, R.E. Bornfreund, W.A. Radford, E.P.G. Smith, J.P. Rosbeck, T.J. de Lyon, J.E. Jensen, and V. Nathan. "HgCdTe/Si materials for long wavelength infrared detectors", J Electron Mater., 33(6): 526-530 (2004). 


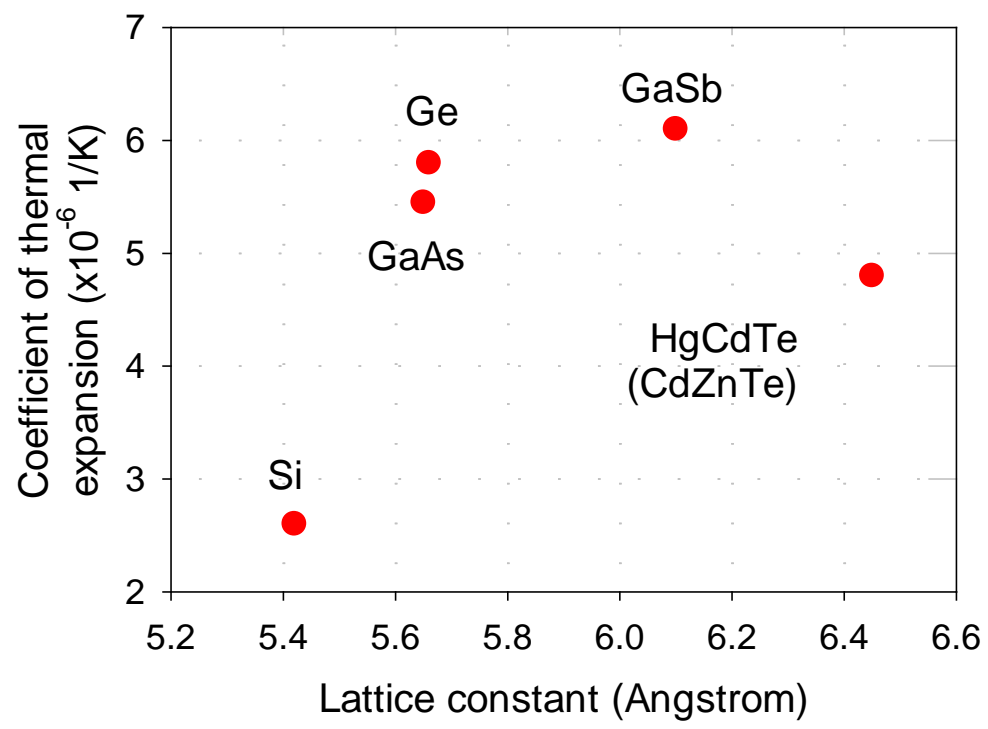

Fig. 1. Lattice and CTE mismatch between $\mathrm{HgCdTe}$ and substrates 

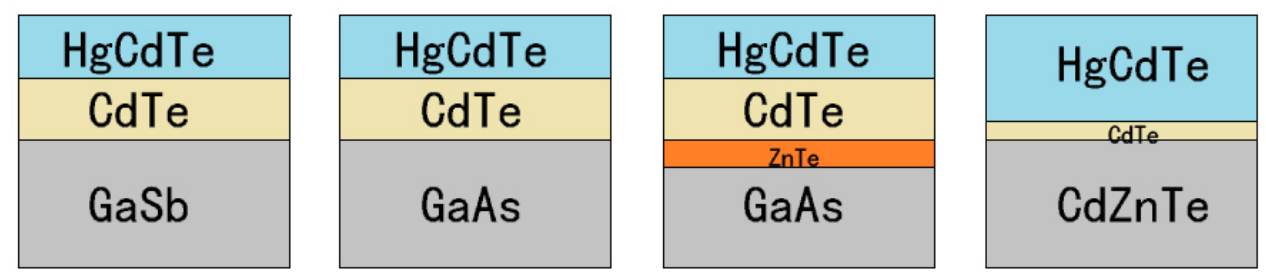

Fig 2 Growth structure for different substrates. (a) GaSb substrate with 5 um buffer layer. (b) GaAs substrate with the same structure of GaSb for compare (c) GaAs substrate with nucleation technology and $5 \mu \mathrm{m}$ buffer (d) CZT substrate with $50 \mathrm{~nm}$ thin buffer layer 


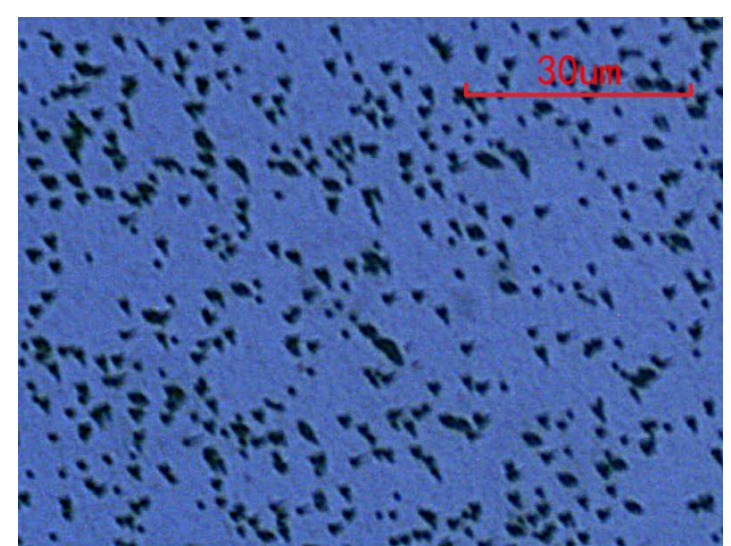

(a) GaSbMCT-1 EPD $=2 \times 10^{6} \mathrm{~cm}^{-2}$

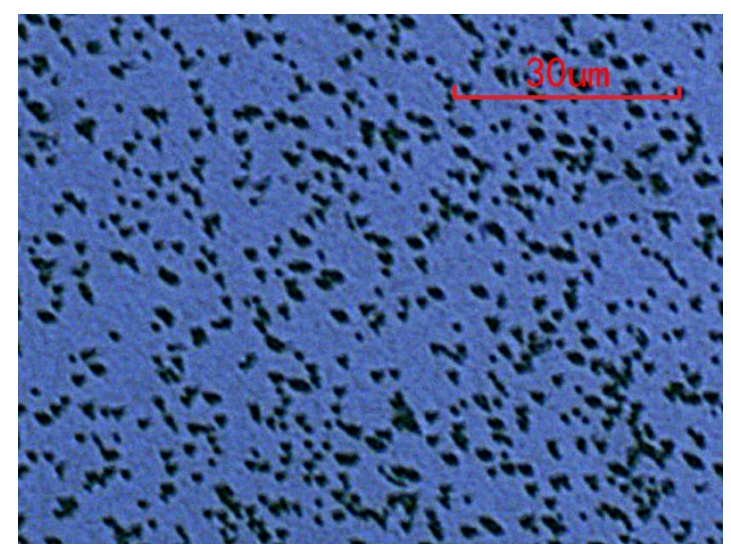

(c) GaAsMCT with ZnTe EPD $=6 \times 10^{6} \mathrm{~cm}^{-2}$

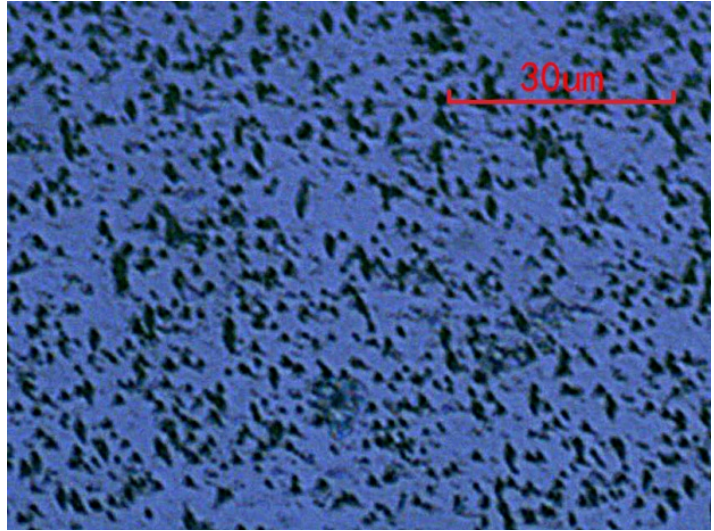

(b) GaAsMCT w/o ZnTe EPD $=2 \times 10^{7} \mathrm{~cm}^{-2}$

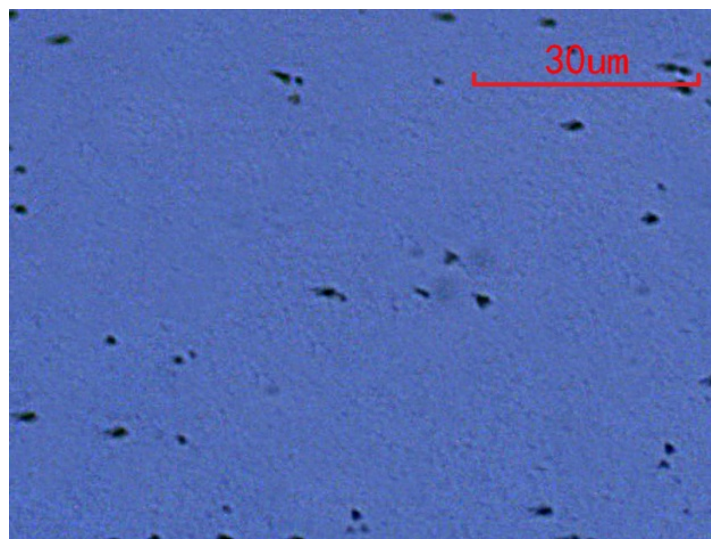

(d) CdZnTeMCT-1 EPD $=2 \times 10^{4} \mathrm{~cm}^{-2}$

Fig 3 EPD on all substrates 


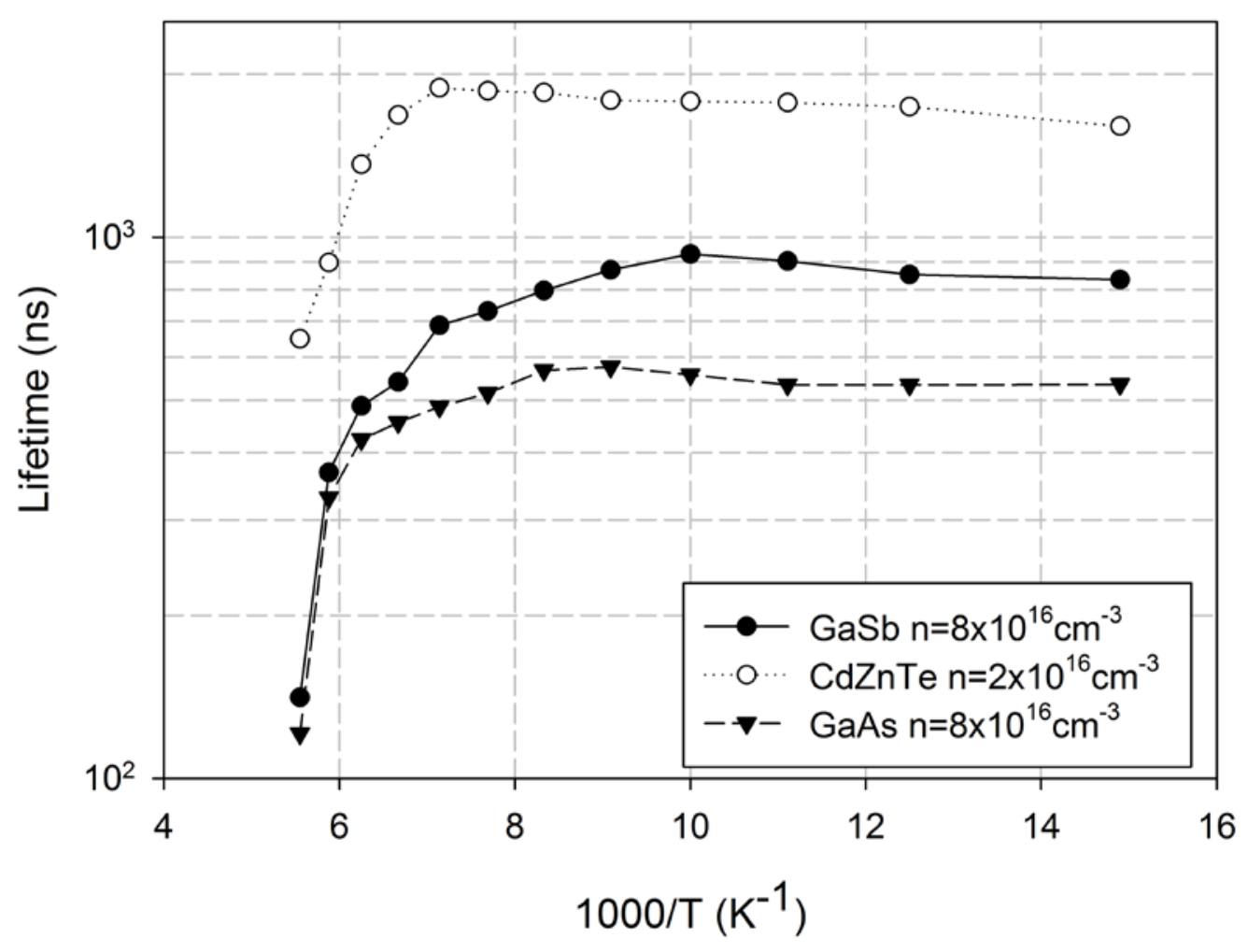

Fig. 4 Minority carrier lifetime for HgCdTe on GaSb, CdZnTe and GaAs, as a function of temperature. 


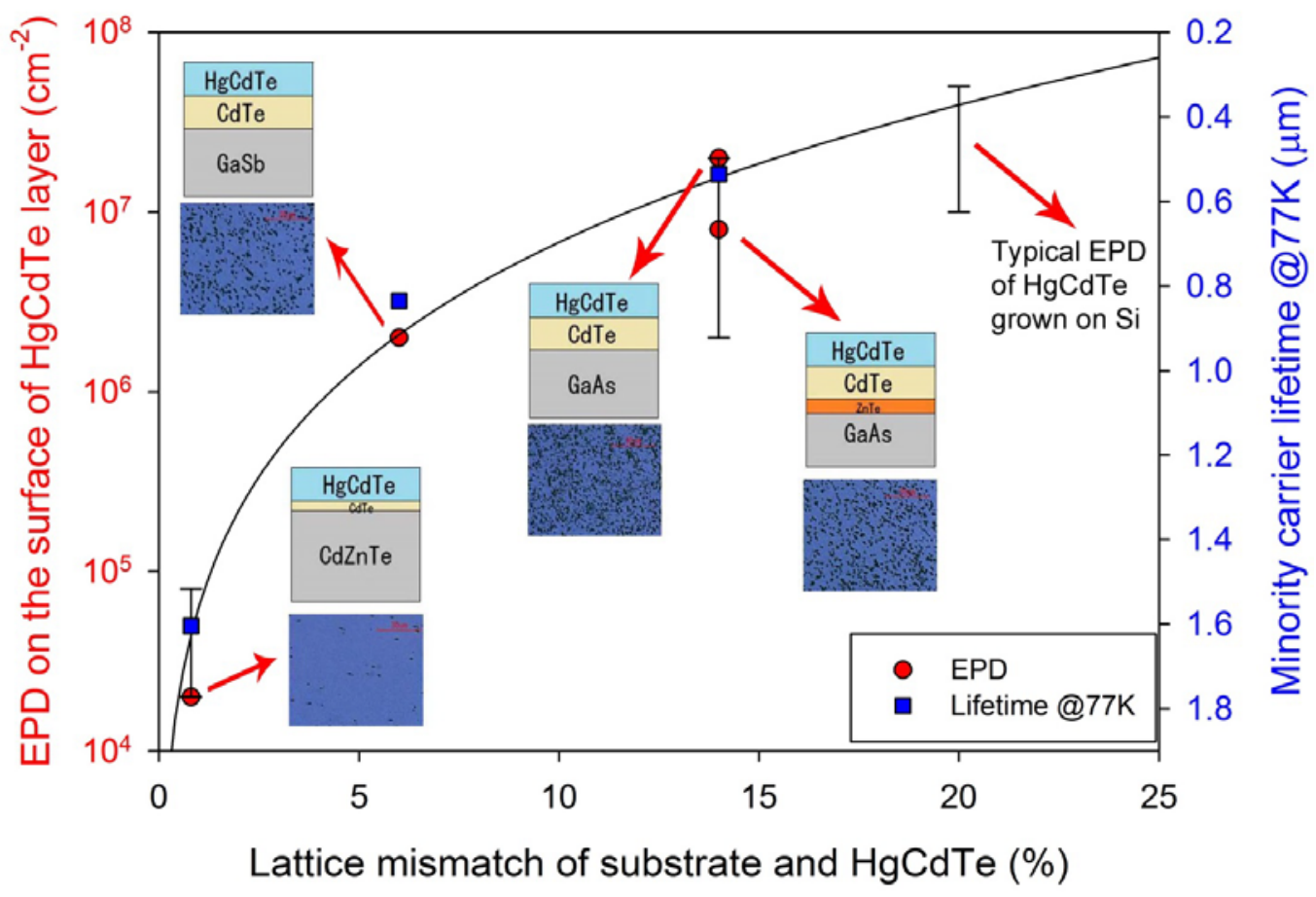

Fig 5 Relationship between modelled strain at substrate/CdTe buffer interface and measured EPD / lifetime on HgCdTe. The error bars represent the typical EPD range of as-grown $\mathrm{HgCdTe}\left(\mathrm{x}^{\sim 0.3)}\right.$ on different substrates from Refs. ${ }^{22-27}$ 
Table I. Material parameters for each layer, composition and thickness data extracted from FTIR.

\begin{tabular}{|c|c|c|c|c|c|c|c|}
\hline Sample No. & Substrate & $\begin{array}{c}\text { Nucleation } \\
\text { Layer }\end{array}$ & $\begin{array}{c}\text { Thickness } \\
\text { of CdTe } \\
\text { (um) }\end{array}$ & $\begin{array}{c}\text { Thickness } \\
\text { of } \\
\text { HgCdTe } \\
\text { (um) }\end{array}$ & $\begin{array}{c}\text { x- } \\
\text { value }\end{array}$ & $\begin{array}{c}\text { XRD } \\
\text { FWHM } \\
(\operatorname{arcsec})\end{array}$ & $\begin{array}{c}\text { EPD } \\
\left(\times 10^{4} \mathrm{~cm}^{-}\right. \\
\left.{ }^{2}\right)\end{array}$ \\
\hline a & GaSb & N & 5.3 & 5.7 & 0.325 & 122 & 200 \\
\hline b & GaAs & N & 5.6 & 5.6 & 0.318 & 191 & 2000 \\
\hline c & GaAs & Y & 5.7 & 5.1 & 0.322 & 98 & 600 \\
\hline d & CdZnTe & N & $10 \mathrm{E}-3$ & 4.7 & 0.298 & 54 & 2 \\
\hline
\end{tabular}

